\title{
Meio Século de Pesquisa Geográfica sobre o Brasil
}

Ivo Marcos Theis ${ }^{1}$

\section{BOOK REVIEW}

Gerd Kohlhepp, Brasilien: Beiträge zur Wirtschafts- und Sozialgeographie aus über 50 Jahren BrasilienForschung (Stuttgart: Franz Steiner Verlag, 2021. 617p.).

1 Doutorado em Geografia Humana pela (Universidade de Tübingen/Alemanha), mestrado em Administração Pública pela Universidade Federal de Santa Catarina/Brasil. Professor e pesquisador do Programa de Pós-Graduação em Desenvolvimento Regional da Universidade Regional de Blumenau/Brasil, ORCID: https://orcid.org/0000-0003-0128-2188, e-mail: theis@furb.br 
"[...] deshalb also gibt es in jeder Geographie der Verbesserung eine konkrete Utopie künftiger Erdbeschaffenheit (gemessen an alter Geographie), die an den Träumen vom irdischen Paradies ihr - durch Phantastik und Mythologie entwertetes - Grenzideal hat". (BLOCH, 1973, p. 926).

"[...] por isto existe em toda geografia da melhora uma utopia concreta da configuração futura da Terra (comparada com a geografia antiga), que traz nos sonhos do paraíso terrestre seu ideal limítrofe - não desvalorizado pela fantasia e mitologia" (BLOCH, 2006, p. 342-343).

É provável que o livro ao qual se dedicam as linhas a seguir não venha a ter muitos leitores brasileiros. No entanto, isso será devido não a eventual desinteresse por seu conteúdo, mas ao fato de que ele foi publicado em alemão, um idioma que permanece tendo penetração relativamente pequena no Brasil. E, não obstante, o conteúdo, propriamente, é de tal interesse que se deveria considerar a possibilidade de sua imediata tradução. Nesta resenha procurar-se-á mostrar algumas das razões que justificariam a sua disponibilidade para o público universitário brasileiro.

O livro é de autoria de Gerd Kohlhepp, geógrafo alemão que tem devotado o melhor de suas energias para conhecer, desvendar e explicar o Brasil. Entre 1958 e 1962 estudou geografia como curso principal, complementando-o com estudos de geologia, economia, história e pré-história, na Universidade de Heidelberg. Ali obteria ainda o mestrado, o doutorado e a habilitação, também, em geografia. Até 1978 lecionou Geografia Humana na Universidade de Frankfurt. Em seguida - e até sua aposentadoria - foi o titular da cátedra de Geografia Econômica e Social, na Universidade de Tübingen. Em 2005 recebeu, então, o título de professor emérito - o que não quer dizer que Gerd Kohlhepp tenha descansado nos últimos $15 \operatorname{anos}^{2}$.

A publicação do livro ao qual se dedicam essas linhas é uma prova de suas invejáveis vitalidade e disposição. Quando se afirmou que suas energias têm sido devotadas a conhecer, desvendar e explicar o Brasil, quis-se dizer, de fato, que sua atenção se concentrou no conhecimento do Brasil (já se verá de quais aspectos), para as suas próprias necessidades e as dos integrantes de seu grupo de pesquisas, em Frankfurt, primeiro, e depois, em Tübingen; no desvendar de facetas e dimensões da

\footnotetext{
2 Para quem quiser se informar melhor a respeito do autor da coletânea aqui resenhada e de sua contribuição para conhecer, desvendar e explicar o Brasil, veja-se Kohlhepp (2006), Dutra e Silva (2020) e Lopes de Souza (2020).
} 
formação geográfica brasileira não elucidados até então, para atender às exigências de suas investigações; e na explicação do que conhecia e desvendava para o público acadêmico - em primeiro plano, alemão, mas também o de outros países, na medida em que publicava os resultados de suas pesquisas em várias línguas, sobretudo, em português e inglês. O livro que se vai resenhar na sequência constitui uma amostra bastante representativa de seus estudos dedicados a conhecer, desvendar e explicar o Brasil.

O livro que aqui se começa a resenhar constitui uma coletânea de textos previamente publicados por Gerd Kohlhepp. O título - que, em português, é "Brasil: contribuições para a geografia econômica e social de mais de 50 anos de pesquisa sobre o Brasil" - parece bastante preciso em termos de seu conteúdo.

Ele é precedido de um prefácio do próprio autor e de uma apresentação assinada pelo Prof. Martin Coy (Universität Innsbruck/Áustria). O primeiro 'capítulo' que constitui uma espécie de introdução geral e revela a afinidade de Gerd Kohlhepp com a tradição da geografia alemã (que tem nos estudos de Leo Waibel sobre o Brasil uma referência inamovível) - aparece logo em seguida. Daí em diante sucedem-se 22 textos, distribuídos por quatro partes principais: à primeira, que trata de temas gerais sobre o Brasil, são dedicados seis textos, publicados no intervalo de 1978 a 2012; a segunda parte está cingida a dois artigos, um ao Sudeste (1997) e outro ao CentroOeste (2014); à terceira, que trata do Sul do Brasil, são dedicados oito textos, publicados no intervalo entre 1966 e 2007; e, finalmente, à última parte, que trata da Amazônia, são dedicados seis artigos, que ganharam a luz entre 1978 e 2007. Ao final, o livro ainda traz a lista completa das publicações de Gerd Kohlhepp sobre o Brasil, a lista de fontes dos textos publicados na coletânea aqui resenhada e três imagens (um mapa e duas fotografias do autor no Brasil, uma de 1965 e outra de 2016).

Como seria impossível discorrer sobre cada um dos capítulos que compõem esta coletânea, adotou-se como critério de abordagem o agrupamento temático, mas considerando-se também o período de publicação dos textos de cada um dos quatro respectivos grupos.

O primeiro deles é, cronologicamente, mas também se se levar em conta o intervalo de publicação, o referente ao Sul. Se é fato que o período aí coberto 
ultrapassa 40 anos, pode-se descontar o primeiro (interessante artigo publicado no curso do doutoramento) e o último (instigante texto, publicado em coautoria, em que faz um sugestivo balanço) dos oito textos para aí, então, se delimitar o período de maior concentração das pesquisas realizadas por Gerd Kohlhepp sobre o Sul do Brasil. Com efeito, os seis 'capítulos' restantes foram publicados entre 1971 e 1989, ou seja, em um intervalo de 18 anos. É, pois, pelo Sul que Kohlhepp inicia sua trajetória de geógrafo dedicado a conhecer, desvendar e explicar o Brasil. No primeiro, publicado em 1966, em que examina aspectos da colonização rural e urbana dos descendentes da imigração alemã em Santa Catarina, mobiliza as primeiras evidências de sua pesquisa de doutorado - a tese "Industriegeographie des nordöstlichen Santa Catarina (Südbrasilien): Ein Beitrag zur Geographie eines deutschbrasilianischen Siedlungsgebietes" foi defendida em 1968. Desse conjunto de oito textos, três foram dedicados a Santa Catarina, três ao Paraná e um ao Rio Grande do Sul; em um deles, Kohlhepp analisou a contribuição da imigração alemã para a colonização e o desenvolvimento econômico da Região Sul. Neste bloco se identifica certa homogeneidade em termos temáticos. O Sul do Brasil é observado, nessas duas décadas entre 1970 e 1990, com as lentes do geógrafo preocupado em conhecer, desvendar e explicar: o processo de ocupação (e aí a relevância da imigração alemã); como, em consequência, se diferenciavam os espaços rural e urbano; a organização da atividade agrícola (por exemplo, o café no Norte do Paraná); e o dinamismo da indústria regional. Cabe notar que Leo Waibel, importante inspiração, passaria a ter presença nas referências de Kohlhepp a partir do terceiro (em termos cronológicos) 'capítulo' da coletânea - que também integra este grupo de textos consagrados ao Sul do Brasil.

O segundo agrupamento de textos, respeitado o critério acima mencionado, desemboca nos 'capítulos' dedicados à Amazônia - o primeiro dos quais tendo ganho a superfície em 1978, quando Kohlhepp ainda publicava sobre o Sul do Brasil. Em princípio, parecerá que o tempo de estudo aos problemas amazônicos tenha sido menor. Contudo, uma breve consulta à lista completa de suas publicações sobre o Brasil revelará o contrário: durante um tempo considerável, que ultrapassa os limites aqui referidos, Gerd Kohlhepp concentrou-se, fortemente, nos problemas da 
Amazônia. Os diversos assuntos que mereceram sua atenção estender-se-iam desde os sérios problemas da colonização agrária (que considerou uma antítese de reforma agrária), passando pelas não menos graves implicações do Programa Grande Carajás, até à complicada situação das populações indígenas em face de conflitos de interesse mal enfrentados pela política regional brasileira. É neste contexto que ganharam maior visibilidade em sua agenda de pesquisa preocupações como: a população do interior do Brasil, os grandes projetos (hidrelétricos, por exemplo), o planejamento em grande escala, as desigualdades sociais e as disparidades inter-regionais. Neste ponto é preciso acrescentar que, como reconhecimento de sua dedicação aos problemas da Amazônia, Kohlhepp integraria o seleto Grupo Consultivo Internacional (IAGInternational Advisory Group) do Programa-Piloto para a Proteção das Florestas Tropicais do Brasil (The Pilot Program to Conserve the Brazilian Rainforest), instituído pelo Governo Brasileiro, pelos países do G7 e pelo Banco Mundial, que durou de 1993 a 2001, tendo-o inclusive presidido por certo período. O IAG tinha por atribuição analisar criticamente o Programa-Piloto e oferecer sugestões para a melhor implementação e execução das medidas previstas para proteger a floresta tropical brasileira. Esta foi, sem dúvida, uma oportunidade singular para o autor lidar com a aplicação dos resultados de seus estudos sobre a Amazônia.

O terceiro bloco é constituído por apenas dois 'capítulos': o mais antigo trata de São Paulo como espaço de concentração industrial, o maior da América Latina. Aqui Kohlhepp dialoga com Milton Santos. O 'capítulo' mais recente é dedicado à produção de etanol. Ou seja, nestes dois textos se entrelaçam a indústria geograficamente concentrada, a 'questão energética' e a proximidade dos loci nos quais uma e outra se manifestam. O texto sobre São Paulo é, especialmente, interessante, por chamar, para poucas páginas, um conjunto de informações estatísticas e documentais, juntamente com dados empíricos - resultado de uma geografia urbana feita à base de observação detalhada sobre todos os elementos presentes no espaço. Assim, não surpreende que, após emergirem dados relativos à evolução da população diante do/a leitor/a, ele/a é confrontado, por um lado, com os guetos ocupados e controlados pela camada superior e, por outro, com os espaços (desprezados pelas autoridades públicas) reservados aos socialmente excluídos. Essa 
mesma megalópole, atravessada pelas contradições dos caóticos processos de industrialização e urbanização que tiveram lugar no Brasil a partir dos anos 1930, constitui a maior cidade industrial alemã. Vale dizer: São Paulo concentrava a maior quantidade de multinacionais alemãs do planeta, se considerada a quantidade de empregados/unidade produtiva/origem do capital/nível político-administrativo. No entanto, o texto sobre a produção de etanol não é menos interessante. A rigor, Kohlhepp preocupara-se desde cedo com as potencialidades energéticas do Brasil, dedicando-se a questionar as opções de política energética que vinham sendo adotadas, sobretudo, ao longo do período em que governavam os militares. Sem descurar do respectivo contexto histórico (por exemplo, a referência ao Proálcool), também aqui a geografia tem um lugar destacado, na medida em que são devidamente considerados os aspectos sociais e ambientais espacialmente diferenciados, relativamente à produção e ao consumo de energia (em específico, do etanol). Embora referido ao Centro-Oeste, o 'capítulo' registra que não apenas o cultivo de cana-deaçúcar, mas também a produção de etanol, tiveram, até recentemente, seu epicentro no estado de São Paulo. Embora integre esta alternativa nos marcos tanto do (hoje bastante criticado) agronegócio brasileiro, quanto das implicações socioecológicas de um avanço na cultura da cana, Kohlhepp deixa questões que instigam a sopesar as escolhas mais sustentáveis para uma transição segura em direção - nos termos de seu amigo Ignacy Sachs - a uma 'civilização verde'.

Por fim, o quarto conjunto de textos abarca temas diversos que não dizem respeito a um ponto específico do território. Contudo, não é porque esses seis capítulos, publicados entre 1978 e 2012, tem o Brasil por palco que neles não se revelem importantes âncoras geográficas. Bem ao contrário, aqui (re) aparecem alguns temas que, inevitavelmente, remetem às formas como indivíduos e coletividades se organizam no espaço. Um deles é relativo aos grandes projetos hidrelétricos, outro, ao agronegócio, outro ainda, ao processo de urbanização e de suas repercussões sobre a evolução da população - para mencionar apenas três. Embora contribuam para jogar luz sobre o 'desenvolvimento' brasileiro que teve lugar nos três decênios entre 1980 e 2010, limitar-me-ei a conferir atenção a outros dois 'capítulos'. Um deles - “A imagem do Brasil à luz dos exploradores alemães do século 
XIX e da primeira metade do século XX"3 - resgata elementos interessantíssimos, como já informa o próprio título, da passagem de viajantes alemães pelo Brasil entre o século 19 e a primeira metade do século 20. Fazendo uso de diversas técnicas, com destaque para mapas e desenhos, mas também para registros históricos, documentos e literatura científica alemã, Kohlhepp oferece aqui um incrível quadro da contribuição de estudiosos - Alexander von Humboldt, Carl Friedrich Philipp von Martius e Georg Heinrich von Langsdorff são apenas alguns dos mais renomados para conhecer, desvendar e explicar o Brasil, em especial, os seus aspectos físicogeográficos e as suas 'populações originárias'. Outro 'capítulo' ao qual cabe, brevemente, referir - "Aspectos econômicos e sócio-geográficos do modelo de desenvolvimento brasileiro e sua integração à ordem econômica mundial"4 - revela um autor mais crítico em relação ao seu objeto de estudo. O texto, propriamente, toma sob a lupa a estratégia de desenvolvimento perseguida pelos governantes militares e suas repercussões sobre campo e cidade, mercado interno e mercado mundial, natureza e sociedade - sempre à base de sólidas evidências empíricas. A novidade, porém, é que aqui as escalas se comunicaram de um modo bastante original: as disparidades inter-regionais estavam condicionadas (não determinadas) pelas rígidas políticas governamentais e por um mercado mundial ainda não 'globalizado'. E para produzir este resultado, Kohlhepp dialogou com estudiosos críticos (Manfred Nitsch, Dieter Senghaas e Manfred Wöhlcke, mas também brasileiros como o então dependentista Fernando Henrique Cardoso, Celso Furtado e Rui Mauro Marini), que naqueles anos apontavam para as limitações de 'modelos de desenvolvimento' como o adotado pelo Brasil durante a então vigente ditadura civilmilitar no Brasil. Ao lê-lo, originalmente, em 1992, me identifiquei imediatamente com sua abordagem questionadora dos rumos do desenvolvimento brasileiro - que ficam evidentes nas quatro incongruências referidas ao final da conclusão.

Como dito acima, seria impossível discorrer sobre todos os capítulos que compõem a coletânea que aqui se resenha. Entretanto, a abordagem empregada, porquanto tenha suas limitações, permitiu compor uma visão global a partir de suas

\footnotetext{
3 "Das Bild Brasiliens im Lichte deutscher Forschungsreisender des 19. und der ersten Hälfte des 20. Jahrhunderts".

4 "Wirtschafts- und sozialgeographische Aspekte des brasilianischen Entwicklungsmodells und dessen Eingliederung in die Weltwirtschaftsordnung".
} 
unidades, agrupadas em quatro conjuntos de textos. Esse quadro de conjunto permite constatar que, do ponto de vista dos temas tratados (respeitada a sua diversidade) e dos métodos adotados (cabe reiterar o extremo cuidado tido com aspectos empíricos, cada argumento sendo fundamentado em evidências obtidas por métodos e técnicas os mais apurados da geografia contemporânea), quase não se verificam interrupções. Há mesmo algumas significativas permanências. Talvez coubesse falar de amadurecimentos, que se revelam na consistência das conclusões de textos mais recentes, decorrência da experiência que o autor foi acumulando ao longo do tempo. Esse quadro permite afirmar, pois, que se está diante de uma obra de referência para os estudiosos do Brasil que dominam o idioma alemão. Uma primeira razão que justifica esta afirmação é que os 'capítulos' foram devidamente avaliados por pares em sua origem, quando submetidos a periódicos ou apresentados para públicos selecionados. Outra razão diz respeito ao conhecimento envolvido, que é científicoacadêmico, mas abarca um domínio de temas e problemas que foram vivenciados por seu autor em campo, em relação com seus interlocutores brasileiros. Uma terceira razão se refere ao largo intervalo de tempo aqui considerado: ele revela, de um lado, dedicação (sim, 'mergulho no objeto') por parte do pesquisador e, de outro, abrangência: afinal, que outros brasilianistas podem exibir uma produção temporalmente tão larga, sem descontinuidades e com essa consistência? Enfim, e para concluir, a coletânea que se acaba de resenhar tem muitas qualidades, que são indissociáveis das reconhecidas virtudes de seu autor. Que as linhas acima hajam contribuído para demonstrar que o conteúdo da coletânea, que reúne 23 instigantes textos de Gerd Kohlhepp, é de tal interesse que se deveria considerar a possibilidade de sua imediata tradução para seu acesso ao público brasileiro.

\section{REFERÊNCIAS}

Ernst Bloch, Das Prinzip Hoffnung, vol 2 (Frankfurt a. M.: Suhrkamp, 1973).

Ernst Bloch. O princípio esperança, vol. 2 (Rio de Janeiro: Contraponto, 2006).

Sandro Dutra e Silva, "Gerd Kohlhepp e as heranças da geografia alemã para os estudos de colonização e desenvolvimento no Brasil: entrevista," HALAC: Historia Ambiental, Latinoamericana y Caribeña 10, 1 (2020): 306-334 <Vista de Gerd Kohlhepp 
e as heranças da geografia alemã para os estudos de colonização e desenvolvimento no Brasil (halacsolcha.org)>.

Gerd Kohlhepp, "Industriegeographie des nordöstlichen Santa Catarina (Südbrasilien): Ein Beitrag zur Geographie eines deutschbrasilianischen Siedlungsgebietes," (Ph. D. diss., Instituto de Geografia/Universität Heidelberg, 1968).

Gerd Kohlhepp, "A contribuição do Centro de Pesquisas sobre a América Latina do Instituto de Geografia da Universidade de Tübingen, Alemanha, para a pesquisa geográfica no Brasil," Geosul 21, 41, (2006): 141-161 <Vista do A contribuição do Centro de Pesquisas sobre a América Latina do Instituto de Geografia da Universidade de Tübingen, Alemanha, para a pesquisa geográfica no Brasil (ufsc.br)>.

Marcelo J. Lopes de Souza, "O Brasil sofre com uma 'guerra ideológica' contra todos os que estão comprometidos contra a destruição da Amazônia: entrevista com Gerd Kohlhepp," Ambientes: Revista de Geografia e Ecologia Política 2, 2 (2020): 398-437 $<26591-98885-1-$ PB.pdf $>$. 